\title{
Putting Small-Scale Mining in Perspective: An Analysis of Risk Perception of a Southwestern Nigerian Community
}

\author{
Sesan Adeyemia, Ayodele Olagunju ${ }^{\mathrm{b} *}$ \\ a Department Urban and Regional Planning, Faculty of Environmental Sciences, University of Lagos, Lagos, Nigeria. \\ b University of Saskatchewan. \\ *Corresponding author's email address: ayodele.olagunju@usask.ca
}

\section{AR T I C LE INF O}

Received: 27-06-2017

Accepted: 06-07-2017

Available online: 31-07-2017

\section{Keywords:}

Environmental impacts;

Small-scale mining;

Risk management;

Residents' tolerance index;

Residents' agreement index.

JEL Classification:

D81; L72; Q01; R11; R58.

\begin{abstract}
A B S T R A C T
Across the developing world, informal small-scale mining is still growing in popularity, so are its significant socio-environmental burdens to the host communities. The assumption that understanding risk tolerance at small scale of mining is important to recommending effective planning approach, in mitigating its environmental impacts, and in promoting environmentally responsible oversight gave rise to this survey. This paper adopts an analytical approach to examine residents' tolerance of the effects of mining in Ijero Local Government in Ekiti State, southwestern Nigeria. Quantitative responses from a systematic sampling of 506 residents are presented with an emphasis on risk perception and management measures. By ranking 21 variables identified through an extensive literature review, residents' tolerance index (RTI) and resident agreement index (RAI) are computed. The results suggest that while residents' risk perception is largely motivated by socio-economic considerations brought about by a major surge in population growth in recent years, there is greater desire for an active public engagement and improved regulatory oversight. The conclusion highlights the value of local capacity building and increased awareness of less risky economic alternatives in successfully implementing long-terms solutions to risks associated with unsustainable mining practice at any scale. The study contributes to the subjects of risk perception and sustainable mining development and offers insight into how capacity could be enhanced through public engagement in jurisdictions with similar policy challenges.
\end{abstract}

(C) 2017 The Authors. This is an open access article under the terms of the Creative Commons Attribution License 4.0, which allows use, distribution and reproduction in any medium, provided the original work is properly cited.

\section{Introduction}

Informal small scale mining is a popular practice and a huge source of income in many resource communities in developing nations. Despite a shared desire to slow down the socio-ecological risks associated with unregulated mining activities, communities often show resistance toward state authorities saddled with oversight responsibility of providing and administering guidelines for best practice in the industry. Such regulations are considered not only restrictive but also sometimes viewed as an attempt at alienating local communities from directly benefiting from the resource extraction despite being the bearers of the socio-environmental burdens arising from the practice. This dissonance presents a puzzle to the subject of risk tolerance of informal mining activities: to what extent are communities able to tolerate the perceived risks of unregulated or weakly regulated mining activities? Few studies explore the nexus between informal mining practices and residents' risk tolerance compared to the number of studies that have examined overall impacts of mining internationally (e.g. Heemskerk 2003; Hayes and Perks 2012). More startling is that such topics is often less visited in the context of developing 
nations and particularly in Nigeria where there has been proliferation of such informal practices (see e.g. Aigbedion and Iyayi 2007). We argue that understanding risk tolerance at small scale of mining is important to recommending effective planning approach, in mitigating its environmental impacts, and in promoting environmentally responsible oversight in the sector. This article uses an analytical approach to examine residents' tolerance of the effects of mining in Ijero Local Government in Ekiti State, southwestern Nigeria. The article proceeds with a review of research on socio-environmental impacts of mining and risk perception theories internationally. We then present the results of a survey of residents in the case study communities to investigate their tolerance level to 21 indicators of mining impacts identified from the literature. Finally, we suggest measures that can help in risk mitigation and effective long term planning practice in the case study and other comparable local settings.

\section{Understanding small-scale mining and its effects on the environment}

\subsection{Socio-environmental impacts of small-scale mining}

How small scale mining is defined is in a state of flux. Mining researchers for instance differentiate between artisanal and small-scale mining based on the tools employed and whether it is formally or informally practiced. Artisanal mining, for example, refers to the use of simple tools and crude methods, the absence of a formal enterprise, and seasonality of the practice, and non-regulated context in which it is mostly practiced (e.g. Lawal 2002; OECD 2002; Limbong et al. 2003; Grätz 2009; Talabi et al. 2015). It is often considered as a component of broader small scale mining activities but it differs in that the latter is expected to be licensed and includes the use of relatively more advanced mining methods (Kambani 1997). Lawal (2002) observed that it will be impossible to consider small scale mining in Nigeria without putting illegal mining in perspective; over $95 \%$ of mining activities in Nigeria are artisanal and another $95 \%$ of these are illegal. In other words, what is often viewed as small scale mining in many developing nations aligns with the "informal, unregulated, undercapitalized and under equipped operations where technical and management skills are lacking" (Lingu and Shikwe, 2007, p. 3). In addition, they are mainly practiced in communities where geological surveys have not been done and the inherent uncertainties often result in higher ecological costs to the environment due to the crude nature of the prospecting and processing practices (Lawal 2002; Fayewa and Oniya 2012; Babatunde et al. 2014; Faircheallaigh et al. 2016)

The economic benefits of small scale mining have received a lot of attention both in local and international literature. Lungu and Shikwe (2007), for instance, argued that mining, especially when diversified to small scale, is critical to poverty reduction as well as economic development of a country. Zamora (2000) also noted that up to 3.5 million people are active in the artisanal and small scale mining sector in Africa. In a study by Akabzaa and Darimani (2001), it is reported that small scale mining has traditionally played an important role in the economy of Ghana. The sector earned the government of Ghana about \$163 million between 1989 and 1994 and provides direct or indirect employment to over 1 million people in the country. More recently, it is estimated that 76 per cent of those who abandoned farming in the eastern region of the country moved into small-scale mining (Boateng et al. 2014). It is further stressed that the sector, if properly managed, could provide employment to many rural communities and generate significant revenue for the government.

The extractive industry at every scale of development has been promoted as an avenue for sustainable resource development practice. This is feasible only if the accrued rent or earnings from the depletion of non-renewable resources are continuously being reinvested into other sustainable undertakings or to support services in the host communities (Labonne and Gilman, 1999). The transition towards a more equitable system will not only require integrated and enabling policy frameworks but will also the commitment of the state actors and the industry to invest in high standard of environmental performance (OECD 2002). To the contrary, state-locals relationships are often characterized by tensions due to perceived inadequacy of the state to re-channel economic benefits of resource extraction to the host community (Omorede 2014). In many instances, informal (often illegal) mining activities have been left unregulated and little attention is placed on the risks of unregulated practices; consequently, there has been surge in practices internationally.

It is no doubt however that despite the economic benefits associated with mining, the extraction process comes with adverse effects on both the human and physical environment. Aigbedion and Iyayi's (2007) study of the environmental effects of mineral exploitation in Nigeria indicates that the three stages of mineral development: exploration, mining and processing have caused different types of environmental damages. It is observed that the environmental damage caused by the small-scale quarrying of laterite, clay, gravel and stone in numerous parts of the country by private entrepreneurs is less but more difficult to control. They noted that the recent search for gemstones in Oyo, Kwara, Edo and Ondo States by illegal miners in particular has resulted in haphazard pitting and trenching of the older granite pegmatites that host the minerals without regards to mining regulations. The 
implication of this is that natural landscape in these areas is now being replaced by hummock topography punctuated by irregular holes.

On the specific risks of small scale mining practices, Hayes and Perks (2012) reported that 24 per cent of child miners work alongside with their mothers in a Democratic Republic of Congo mine. They identify the social consequences of such practice to include the risk of contamination from minerals, having to be absent from school, and the difficulty of coping with formal education when they are later released to attend. In an earlier work by Heemskerk (2003), it is observed that long-term involvement in mining activities is directly relative to the level of risk tolerance exhibited by residents in a Suriname artisanal community. That is, the longer the length of stay the more risk tolerant residents become. It is further observed that factors such as income level, personal injury, and death of family members often influence the decision to continue or quit involvement in mining activities. The effects of children exposure to mercury in gold mining areas in Indonesia and Zimbabwe have also been reported (e.g. Bose-O'Reilly et al. 2008, 2010) as well as the politics of risks associated with mining development in Ghana and Burkina Faso (e.g. Armah et al. 2013; Luning 2014).

The context of the current case study offers little difference from the cases reviewed above. Lar et al. (2014) narrated how the incident of lead poisoning in northern Nigeria caused the death of more than 400 children. Specifically, in a study carried out by Babatunde et al. (2013) in the study area, they reported workers' exposure to various physical, chemical, and ergonomical hazards including physical injuries (45.8\%), chronic cough (33.1\%), other respiratory symptoms like mucoid/bloody sputum (17.8\%), and progressive breathlessness $(22.9 \%)$ among the residents sampled. However, the fact that many other combinations of explanatory variables specific to the community have not been explored in any previous studies suggests the need to understand factors underlying the tolerance of residents of mining communities despite the observable risks. Given this gap in knowledge, the Ijero community represents an ideal context in which to study the risk tolerance potential of residents regarding mining activities, and thus to gain insight into the subject in the Nigerian and developing nations' context at large.

\subsection{Theories of risk perception and tolerance}

There is extant research on risk perception across multiple disciplines especially at the interface of humanenvironment interaction. As a result, we now have a better understanding of the key attributes of risk perception in its various psychological, cognitive and institutional dimensions. Many scholars agree that the knowledge of environmental risk perception may facilitate the development of an effective, context-specific risk management strategies, including risk communication and institutional responses (e.g. Steg and Sievers 2000; Crickette et al. 2012; Galizzi and Tempesti 2014). Perhaps the most important shift in risk perception theory in recent works has been a move away from a conceptualization of risk perception in a fragmented, issue-specific sense. More recent theories of risk perception view it as an integrated process that requires a transdisciplinary approach.

In a recent work by Inouye (2014) which explores theories related to risk perception and risk tolerance, the author highlights six notable theoretical trajectories that have shaped the discourse over the past four decades. According to Inouye, first, there is a protection motivation theory that is rooted in the belief that individuals take protective actions when there are motivations and incentives to do so. In particular, past accidents or injuries tend to increase risk awareness, however the cycle of motivation can only be complete when there are tools and skills to take necessary preventive actions. Second, risk compensation/risk homeostasis theory, a very popular theory in transportation research, suggests that risk-taking behaviour has direct relationship with the level of safety measures that is in place within an organization. For instance, a mining worker might forfeit other safety measures when protective equipment is provided. Third, situated rationality theory which argues that despite tendency to assume that risk-takers are simple "crazy" there are often rational justifications for why people take risks, which may include both extrinsic (e.g. speed/faster completion of tasks over safety measures) and intrinsic (a teen seeking peer approval or ego over safe driving) incentives. Fourth, Inouye highlights the habituated action theory which argues that people exhibit high-risk behaviour where there has been a history of success repeating such risk action without consequences (e.g. texting and driving). In this case, "risk taking can lead to a vicious cycle of more dangerous behavior if negative consequences aren't swiftly realized" (p. 7) and thus high risk tolerance correlates with low risk perception in individuals. The fifth theory-social action theory- is based on the influence of peer pressure or community perception of risk and the tendency to conform due to the positive social meaning attached to high-risk behaviours. The author argues that social action theory can be leveraged for positive outcomes in a work environment with an established culture of safety. The social action theory is similar to the sixth theory i.e. social control theory, but differs in the sense that risk perception and tolerance are directly connected to the level of involvement of individuals in promoting safety awareness or hazard identification in the workplace, some form of psychological empowerment and sense of belonging within the organization.

Among the theories discussed, the situated rationality theory considerably influences risk perception and tolerance in the context of small scale mining, but more from the dimension of extrinsic motivation (i.e. doing an 
activity for instrumental reasons) than an intrinsic one (i.e. doing it for its own sake) (Meyer and Gagne 2008). While level of knowledge regarding risk of unsafe practices may be moderately high among mining workers, the potential economic gains and the absence of incentives for safe practices may be a major driving force. The situated rationality perspective explains why small-scale mining regions may be perceived as centres of political tensions, particularly due to the perceived inadequacy of the state to re-channel economic benefits of resource extraction to the host community (Omorede 2014). Miners in an unregulated environment tend to know the consequences of their actions, so a risk that looks unacceptable to the uninformed is actually being well managed due to such situated rationality. Despite this, there is agreement in risk management literature that attitude toward risk is context-specific (e.g. Galizzi and Tempesti 2014) and may be directly related to the tendency to believe that a negative event is less likely to occur and that an individual is more adept at averting it in the event that it occurs, what Inouye 2014 describes as optimism bias. Having established that current mining practices in our case study have been judged to be unsafe, this study explores some contextual factors that might have enabled this optimism bias among miners and advances some recommendations both at the local and institutional levels of resource governance.

\section{Methods}

\subsection{Case study: Ijero informal mining industry}

Ijero Local Government Area is in Ekiti State, southwestern Nigeria with its component townsincluding: Ijero, Ara, Epe, Araromi, Oke-oro, Iroko, Ayegunle, Temidire, Ilukuno, Ikoro, Ipoti, Odo-owa, Iloro and Ijurin (figure 1). The entire area belongs to the Basement Complex of southwestern Nigeria with the pegmatite areas hosted by three petrologic units i.e. medium to upgrade politic gneisses, low pressure amphibolites, and granitic rocks (Ale et al. 2014). According to Ogungbemi et al. (2014), the pegmatite from the study area form an intrusion into the older rock of biotite gneiss that occupies its central part, covering about three quarter of the total land mass. Tantalite, topaz, quartzite, limestone, tin, mica, tourmaline, feldspar, clays, beryl (aquamarine) and cassiterite have been extracted in the area. These solid mineral resources, though exploitation largely based in the informal sector, is a huge source of economic activities in the area, and a main contribution of foreign exchange earnings to the government. Since 1996, mining activities have led to inward migration to communities in and around the local government area, which in-turn has led to increase in population. For instance, official census reports indicate that the local government population grew from 93,286 to 221,405 between 1991 and 2006 (Ekiti State Government 2014) - an approximately $240 \%$ increase. Despite this, few attempts have been made to study the effects of mineral mining activities in the area, and none has focused on risk perception and tolerance. In particular, little documentation exists on the locational and environmental peculiarities of Ijero communities compared to studies on oil and gas sectors in the Niger Delta's, which have received a disproportionate attention over the past decades.

\subsection{Data collection and analysis}

Primary data were collected through field observation and administration of questionnaires. A total of 5,540 residential buildings were identified which constituted the sampling frame for the survey. Systematic sampling technique was used to identify a sample size of 554 (10 per cent). ${ }^{1}$ With a response rate of $91.3 \%, 506$ questionnaires returned formed the basis of the data analysis. Table 1 shows the seven political wards in Ijero Local Government Area and the number of buildings in

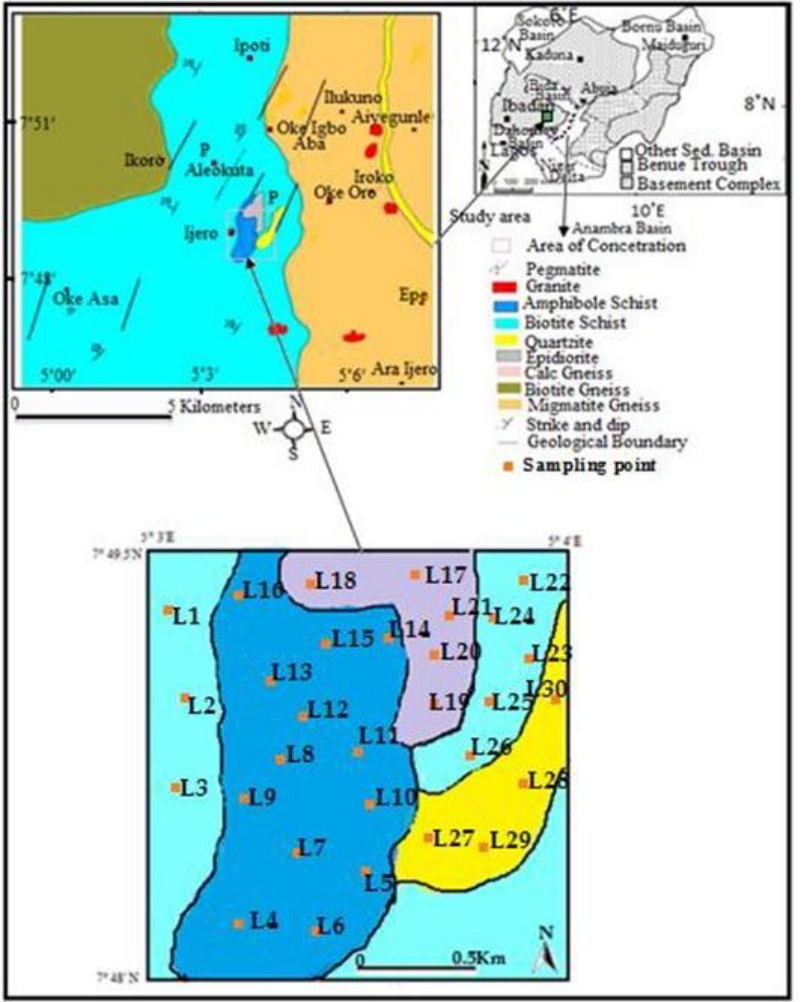

Figure 1: Location and Geological map of Ijero-Ekiti (Source: Okunlola and Akinola 2010)

each ward. The table also indicates the sample size selected in each ward based on $10.0 \%$ systematic sampling. The rationale for adopting a questionnaire survey was to allow for wider inputs than was possible through interviews with selected few participant and to ensure aggregate responses represent shared interests and opinions in the community.

1 The first house was randomly selected followed by selection of every tenth building along the line of movement. 
Table 1: Political wards, number of buildings and sample size

\begin{tabular}{lrr}
\hline Political ward & No of building & Household selected for survey $(10.0 \%)$ \\
\hline Ijero A & 830 & 83 \\
Ijero B & 915 & 92 \\
Ijero C & 884 & 88 \\
Ijero D & 780 & 78 \\
Ekamarun & 670 & 67 \\
Ipoti 1 & 710 & 71 \\
Ikoro & 750 & 75 \\
Total & 5540 & 554 \\
\hline
\end{tabular}

Source: Ekiti State Government (2014)

Data collected were analyzed using descriptive and inferential statistics. Descriptive statistics such as cross tabulation and percentages were used in the analysis of relationship between respondents' socio economic attributes and physical environmental effects of mining activities. These include educational attainment and occupation, education and ailments, occupation and ailments, income and ailments among others. Residents' Tolerance Index (RTI) was used in the analysis of the level of tolerance by respondents to physical environmental effects of mining activities while Residents' Agreement Index (RAI) measures the level of agreement of respondents to the recommended measures for controlling mining activities in the area. The aggregate responses are used to draw inferences and conclusions on risk tolerance in the area as presented in the next section.

\section{Results and discussion}

\subsection{Socio-economic characteristics of respondents}

The spectrum of participants involved in the survey encouraged representativeness of opinions across different social categories. The detailed description of residents' socio-economic characteristics is provided in Table 2 . The data collected showed that the gender configuration of the respondents is a reflection of a largely patriarchal household headship observable in most sub-Saharan African societies: 57.5 per cent male against 41.3 per cent female. As for the age distribution, the spread indicates a span across active working population; over 78 per cent of respondents are between age 21 and 60 . The educational level reveals that the majority $(n=342)$ had at least a secondary education although about 17 per cent still indicated no formal education. The information on residents' occupation was also sought; the results show that most respondents are either civil servants $(n=281)$ or traders $(n=124)$ while only 4.1 per cent engage exclusively in mining-related activities. About 41 per cent of respondents earn below $\$ 10,000$ and another 18.2 per cent earn between $\$ 10,000$ and $\$ 20,000$, which is an indication that almost half earn below national recommended monthly minimum wage of N18,000 (approx. \$120) ${ }^{2}$. Beyond the influence of gender, age, educational level, occupation, and income in determining risk tolerance, residents' length of stay has been found to have a profound influence on risk perception (see Heemskerk 2003). Thus, in this case, the residents' length of stay in the community is sought in the questionnaire survey. Responses showed that the majority $(n=281)$ had lived in the community for less than 10 years, which can be explained by mining-induced inward migration to the community over the past two decades as earlier stated.

Table 2: Selected socio-economic characteristics of respondents

\begin{tabular}{lrr}
\hline Gender & No. of Respondents & Percentage \\
\hline Male & 291 & 57.5 \\
Female & 209 & 41.3 \\
No response & 6 & 1.2 \\
\hline Age Groups & & \\
\hline $18-20$ & 28 & 5.5 \\
$21-30$ & 133 & 26.3 \\
$31-40$ & 122 & 24.1 \\
$41-50$ & 77 & 15.2 \\
$51-60$ & 65 & 12.9 \\
Above 60 & 70 & 13.8 \\
No response & 11 & 2.2 \\
\hline Level of Education & & \\
\hline No formal education & 87 & 17.2 \\
Primary & 73 & 14.4
\end{tabular}

${ }^{2} \mathrm{~A}$ US dollar exchanges for 150 Nigerian naira as of the time the data were collected 


\begin{tabular}{lrr} 
Secondary & 107 & 21.1 \\
Tertiary & 235 & 46.5 \\
No response & 3 & 0.8 \\
\hline Occupation & & 16.4 \\
\hline Farming & 83 & 24.5 \\
Trading & 124 & 36.0 \\
Civil service & 182 & 14.0 \\
Artisan & 71 & 4.2 \\
Mining & 21 & 0.2 \\
Student & 1 & 4.7 \\
No response & 24 & 100.0 \\
Total & 506 & 41.3 \\
\hline Income (Naira) & & 18.2 \\
\hline Less than 10,000 & 209 & 10.1 \\
$10,000-20,000$ & 92 & 4.1 \\
$20,000-30,000$ & 51 & 2.2 \\
$30,000-40,000$ & 21 & 4.5 \\
$40,000-50,000$ & 11 & 19.6 \\
Above 50,000 & 23 & \\
No response & 99 & 55.5 \\
\hline Length of Residence & & 15.6 \\
\hline $1-10$ years & 281 & 5.2 \\
$11-20$ years & 79 & 4.9 \\
$21-30$ years & 26 & 0.4 \\
$31-40$ years & 25 & \\
$>$ 40 years & 93 & 2 \\
No response & 2 & \\
\hline & &
\end{tabular}

\subsection{Residents' perception of the effects of mining activity}

The residents' perception of the effects of mineral extraction process in the study area was measured through the residents' tolerance index (RTI). In a previous study, Afon (2006) used residents' satisfaction index in identifying environmental attributes necessary for the rehabilitation of the core area of Ogbomoso, Oyo State (Nigeria). Our study identifies 21 variables relating to mining effects from literature to measure risk tolerance of respondents. The assumption is that tolerance level corresponds directly to perception of mining effects on a community. A high level of tolerance is an indication that mineral extraction has a positive effect and vice versa. To calculate the RTI, the residents rated each variable using one of the five ratings: very tolerable, tolerable, just tolerable, not tolerable and not at all tolerable. Each of this was respectively assigned a value of 5, 4, 3, 2 and 1 . The summation of weight value (SWV) for each mining effect is obtained through the addition of the product of responses for each rating of the mining effect and their respective weight values. Mathematically, this is expressed as:

$$
\mathrm{SWV}=\sum_{i=1}^{5} P_{i} V_{i}
$$

Where: SWV is the summation of weight value,

$P_{i}$ is the respondent rating a of particular mining effect and

$V_{i}$ is the weight value assigned to each variable.

The RTI for each variable effect is arrived at by dividing the summation of weight value by the addition of the number of respondents to each of the five ratings. This is expressed mathematically as:

$$
\mathrm{RTI}=\frac{S W V}{\sum_{1}^{5} P_{i}}
$$

Where RTI is the residents' tolerance index, SWV and $P_{i}$ are as defined previously. The closer the RTI of a particular variable is to five, the higher is the assured residents' tolerance about the mining effects. 


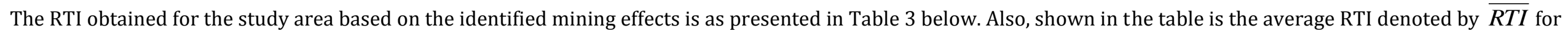

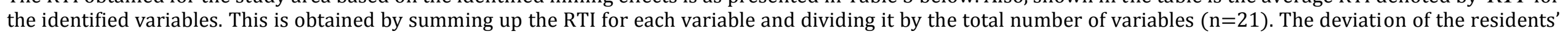

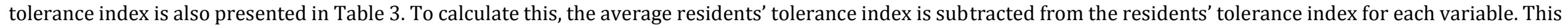

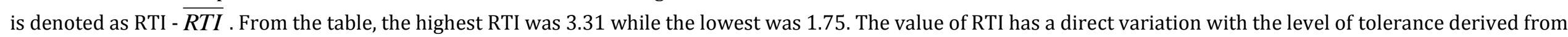

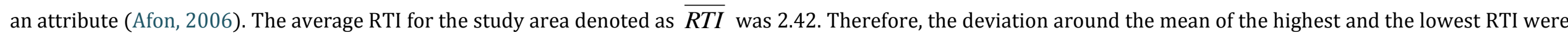

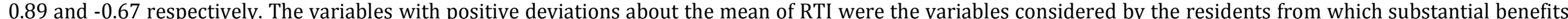

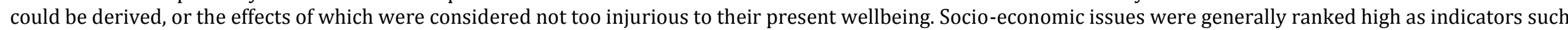

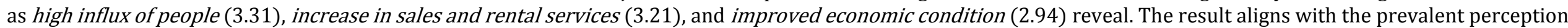

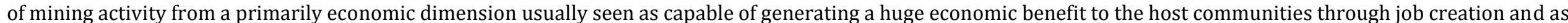

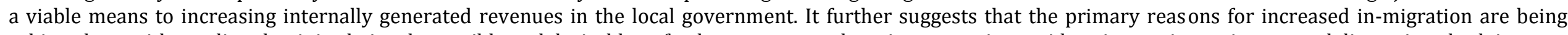

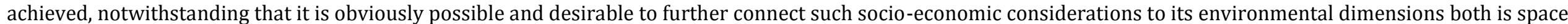

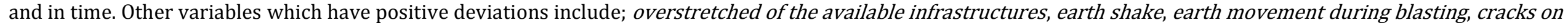
building due to blasting, and landslide.

Table 3: Residents tolerance index on the effect of mining activity

\begin{tabular}{|c|c|c|c|c|c|c|c|c|c|c|}
\hline \multirow{2}{*}{$\begin{array}{l}\mathrm{S} / \\
\mathrm{N}\end{array}$} & \multirow[t]{2}{*}{ Effect of mining } & \multicolumn{8}{|c|}{ Rating and weight value } & Deviation \\
\hline & & $\begin{array}{r}\text { Very Tolerable } \\
\text { WV (5) }\end{array}$ & $\begin{array}{r}\text { Tolerable } \\
\text { WV (4) }\end{array}$ & $\begin{array}{r}\text { Just Tolerable } \\
\text { WV (3) }\end{array}$ & $\begin{array}{r}\text { Not Tolerable } \\
\text { WV (2) }\end{array}$ & $\begin{array}{r}\text { Not at all Tolerable } \\
\text { WV (1) }\end{array}$ & SWV & RTI & $\mathrm{RTI}-\overline{R T I}$ & $(\mathrm{RTI}-\overline{R T I})^{2}$ \\
\hline 1 & High influx of people & 136 & 73 & 73 & 89 & 61 & 1430 & 3.31 & 0.89 & 0.7221 \\
\hline 2 & Increase in sales and rental prices & 122 & 74 & 78 & 88 & 70 & 1386 & 3.21 & 0.79 & 0.6421 \\
\hline 3 & Improve economic condition & 144 & 11 & 11 & 86 & 66 & 1035 & 2.94 & 0.52 & 0.2704 \\
\hline 4 & Overstretched infrastructure & 111 & 54 & 50 & 78 & 115 & 1192 & 2.92 & 0.50 & 0.2500 \\
\hline 5 & Earth shake & 74 & 78 & 68 & 108 & 98 & 1200 & 2.80 & 0.38 & 0.1444 \\
\hline 6 & Earth movement during blasting & 54 & 88 & 70 & 115 & 96 & 1158 & 2.74 & 0.32 & 0.1024 \\
\hline 7 & Cracks on building due to blasting & 83 & 47 & 48 & 126 & 119 & 1118 & 2.64 & 0.22 & 0.484 \\
\hline 8 & Landslide & 74 & 51 & 53 & 134 & 112 & 1113 & 2.63 & 0.21 & 0.0441 \\
\hline 9 & Dust in air & 61 & 38 & 46 & 107 & 162 & 971 & 2.35 & -0.07 & 0.0049 \\
\hline 10 & Illegal mining & 58 & 48 & 52 & 111 & 173 & 1033 & 2.34 & -0.08 & 0.0064 \\
\hline 11 & Loss of farmland & 63 & 55 & 53 & 91 & 196 & 1072 & 2.34 & -0.08 & 0.0064 \\
\hline 12 & Land dispute & 56 & 46 & 40 & 106 & 189 & 985 & 2.25 & -0.17 & 0.0289 \\
\hline 13 & Blocking of drains & 31 & 50 & 46 & 136 & 142 & 907 & 2.24 & -0.18 & 0.0324 \\
\hline 14 & Erosion due to mining excavation & 47 & 37 & 35 & 150 & 152 & 940 & 2.23 & -0.19 & 0.0361 \\
\hline 15 & Smokes & 48 & 34 & 50 & 106 & 178 & 916 & 2.20 & -0.22 & 0.0484 \\
\hline 16 & Increase in crime rate & 28 & 49 & 63 & 144 & 159 & 972 & 2.19 & -0.23 & 0.0529 \\
\hline 17 & Fumes & 36 & 32 & 44 & 116 & 178 & 850 & 2.10 & -0.32 & 0.1024 \\
\hline 18 & Domestic animal mortality & 22 & 48 & 37 & 105 & 217 & 840 & 1.96 & -0.46 & 0.2116 \\
\hline 19 & Communal clash & 26 & 32 & 32 & 123 & 214 & 814 & 1.91 & -0.51 & 0.2601 \\
\hline 20 & Siltation & 22 & 16 & 39 & 118 & 211 & 738 & 1.82 & -0.60 & 0.3600 \\
\hline \multirow[t]{2}{*}{21} & Run off to streams & 16 & 20 & 25 & 137 & 216 & 725 & 1.75 & -0.67 & 0.4489 \\
\hline & Total & $1312^{*}$ & $981 *$ & $1013^{*}$ & $2374 *$ & $3124^{*}$ & 21395 & 50.87 & & 3.8753 \\
\hline
\end{tabular}

Source: Author's field survey, 2010, Note: *Multiple responses 


$$
\begin{aligned}
& \sum R T I=50.87, \overline{R T I}=\frac{\sum R T I}{(N=21)}=\frac{50.87}{21}=2.42 \quad \text { Variance }=\frac{\sum(R T I-\overline{R T I})^{2}}{N}=\frac{3.8753}{21}=0.1345 \\
& \text { Standard deviation (SD) } \sqrt{\text { Variance }}=\sqrt{0.1845}=0.42953463 \quad \mathrm{SD}=0.43
\end{aligned}
$$$$
\text { Co-efficient of variation }=\left[\left(\frac{S D}{R T I}\right) \times 100\right] \%=\left[\left(\frac{0.43}{2.42}\right) \times 100\right] \%=17.77 \%
$$

Despite the positive deviation of the above variables around the mean of RTI, the residents' perceptions on these variables fell between just tolerable and not tolerable. This indicates low level of tolerance by the residents. Field observation shows that many of the physical impacts identified (particularly those related to earth movement) are not currently evident; they could however be flagged as areas of concern in hazard planning for the communities. This finding corroborates Aigbedion and Iyayi (2007), that mining operation may trigger off certain geological hazards such as landslide, earth shake, earth movement, flooding erosion and tremors together with their secondary effects. The variables with negative deviation around the mean of RTI were the variables that the residents show low level of tolerance for, or considered to affect them negatively. Such variables include: dust pollution (-0.07), illegal access (-0.08), loss of farmland (-0.08), land dispute (-0.17), blocking of drains $(-0.18)$, erosion due to mining excavation(-0.19), smokes(-0.22), increase in crime rate $(-0.23)$, fumes $(-0.32)$, loss of domestic animals in the mine(-0.46), communal clash(-0.51), siltation $(-0.60)$, and run off to streams $(-0.67)$.

The residents' perception on variables such as illegal mining, loss of farmland, and land dispute falls between just tolerable and not tolerable, while residents' perception on siltation and mine runoff to streams falls between not tolerable and not at all tolerable. This implies low level of tolerance by the residents. For instance, diarrhoea infections which are often reported in the area may have led to the perception that contaminated stream sources due to mining activities are responsible; hence low tolerance for the variable. Similarly concerns over loss of farmland, loss of domestic animals, land dispute, and communal clash are expressed as serious social problems capable of disrupting peaceful coexistence in the area. The computed RTI variance was 0.1845 , with a standard deviation of 0.43 and co-efficient of variance of $17.77 \%$. The scattering of responses around the mean of RTI was low; in essence, the aggregate level of tolerance expressed by residents was close and not too far from each other.

Overall, 19 (90.5\%) variables received low level of tolerance while $3(9.5 \%)$ received moderate to high level of tolerance, yet the residents support continuation of mining activities in the community. This is an indication that residents are more concerned about the social and economic effects of mining than its biophysical effects on the environment, despite observable evidence that indicates significantly high risk mining practices (see Figure 2). Residents' low level of concerns about biophysical effects are not misplaced given that a recent study by Faweya and Oniya (2012) on the radiological safety of the study area shows that all heavy metals in their
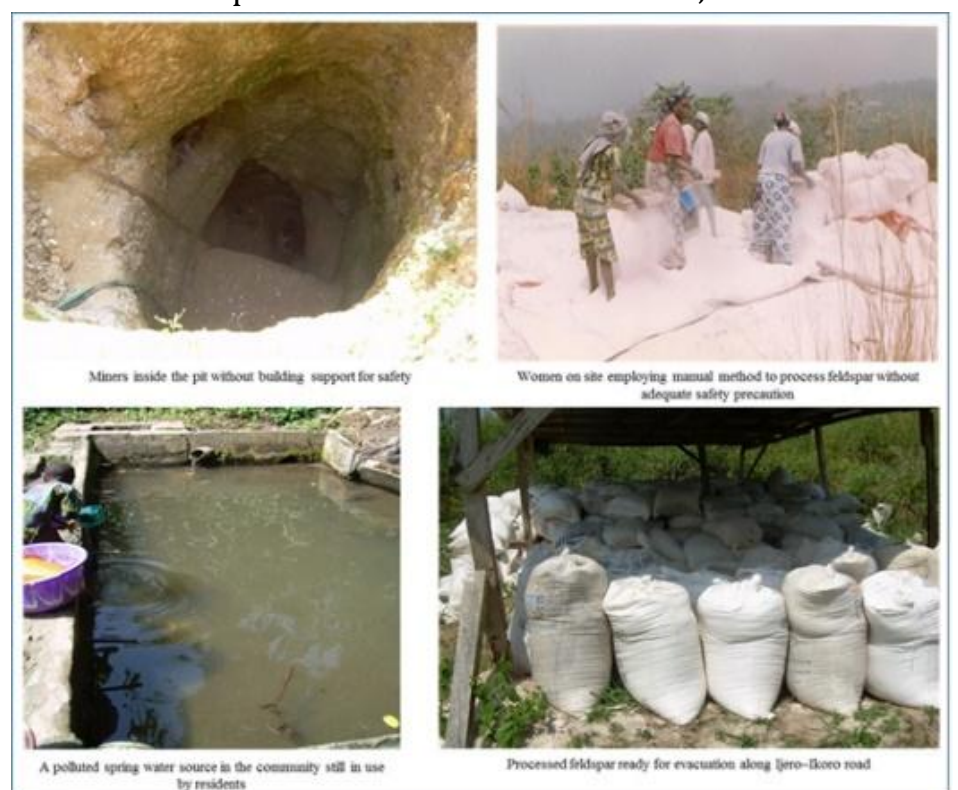

Figure 2: Photos showing different environmental risks of mining in the community samples are within acceptable limit and do not pose significant safety concerns, though delayed effects are not factored into their analysis.

\subsection{Residents' perception of measures for controlling mining activity}

The RTI was modified to a residents' agreement index (RAI) to measure the level of agreement of respondents to the suggested measures for controlling mining activities. To achieve this, the residents rated five suggested measures using any one of the five ratings: very much agree, agree, just agree, not agree and not at all agree to 


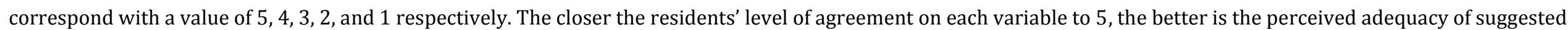

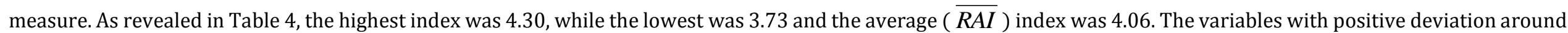

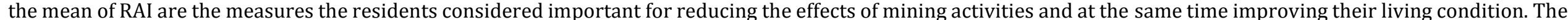

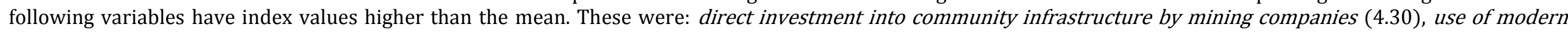
equipment by miners (4.22), and closer monitoring by responsible authorities (4.07). Their deviations around the mean of RAI were: $0.24,0.17$ and 0.01 respectively.

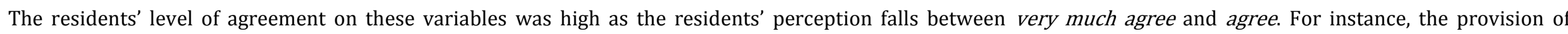

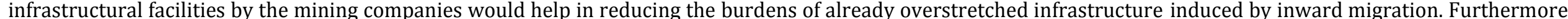

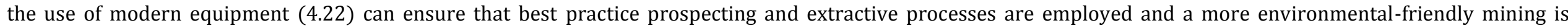

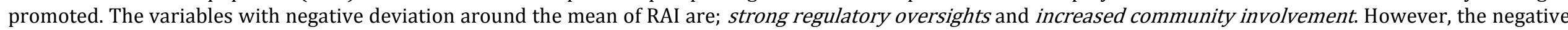

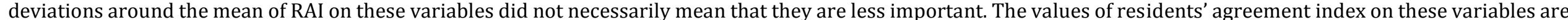
3.91 and 3.73 respectively and their perception falls between just agree and agree.

Table 4: Residents perceived measure for controlling mining activity

\begin{tabular}{|c|c|c|c|c|c|c|c|c|c|c|}
\hline \multirow[t]{2}{*}{$\mathrm{S} / \mathrm{N}$} & \multirow[t]{2}{*}{ Effect of mining } & \multirow[b]{2}{*}{$\begin{array}{r}\text { Very much } \\
\text { agree WV (5) }\end{array}$} & \multirow[b]{2}{*}{$\begin{array}{r}\text { Agree } \\
\text { WV (4) }\end{array}$} & \multirow[b]{2}{*}{$\begin{array}{r}\text { Just agree } \\
\text { WV (3) }\end{array}$} & \multirow[b]{2}{*}{$\begin{array}{r}\text { Not agree } \\
\text { WV (2) }\end{array}$} & \multirow[b]{2}{*}{$\begin{array}{r}\text { Not at all } \\
\text { agree WV (1) }\end{array}$} & \multirow[b]{2}{*}{ SWV } & \multirow[b]{2}{*}{ RAI } & \multicolumn{2}{|c|}{ Rating and weight value } \\
\hline & & & & & & & & & $\begin{array}{l}\text { Deviation } \\
\text { RAI }-\overline{R A I}\end{array}$ & $(\mathrm{RAI}-\overline{R A I})^{2}$ \\
\hline 1 & Provision of basic infras. by mining companies & 271 & 142 & 37 & 21 & 15 & 2091 & 4.30 & 0.25 & 0.0625 \\
\hline 2 & Improvement in mining methods and tools & 192 & 245 & 35 & 12 & 7 & 2076 & 4.22 & 0.17 & 0.0289 \\
\hline 3 & Constant monitoring by responsible authorities & 153 & 248 & 55 & 22 & 6 & 1972 & 4.07 & 0.02 & 0.0004 \\
\hline 4 & Stronger legislative instrument & 153 & 201 & 97 & 36 & 8 & 1940 & 3.91 & -0.14 & 0.0196 \\
\hline 5 & Direct comm. involvement in mining activities & 117 & 214 & 82 & 59 & 16 & 1821 & 3.73 & -0.32 & 0.1024 \\
\hline & Total & $733^{*}$ & $1050^{*}$ & 306 & 150 & 52 & 9936 & 20.23 & & 0.2158 \\
\hline
\end{tabular}

Source: Author's field work, 2010*: Multiple responses

$$
\sum R A I=20.28, \overline{R A I}=\frac{\sum R A I}{(N=21)}=\frac{20.23}{5}=4.046 \overline{R A I}=4.05 ; \text { Variance }=\frac{\sum(R A I-\overline{R A I})^{2}}{N}=\frac{0.2138}{5}=0.04276
$$

Standard deviation (SD) $\sqrt{\text { Variance }}=\sqrt{0.04276}$

$\mathrm{SD}=0.206784912=0.20$

Co-efficient of variation $=\left[\left(\frac{S D}{\overline{R A I}}\right) \times 100\right] \%=\left[\left(\frac{0.2}{4.05}\right) \times 100\right] \%=4.938271=4.93 \%$

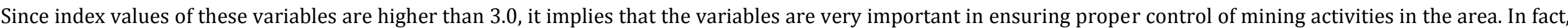

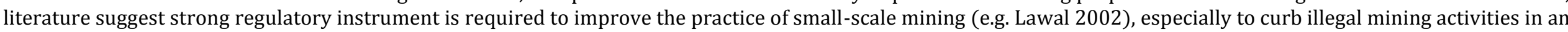
area such as Ijero where regulatory oversight is reportedly weak. And to ensure sustainable extractive practice, public participation is highly important. The computed 
RAI variance was 0.04276 , with a standard deviation of 0.20 and co-efficient of variation of $4.93 \%$. Based on this computation, it could be deduced that the scatter around the mean of RAI was low, the level of responses by the residents were very close and not far from each, which implies that all measures are considered relevant to a more sustainable mining regulation in the community.

Since index values of these variables are higher than 3.0, it implies that the variables are very important in ensuring proper control of mining activities in the area. In fact, literature suggest strong regulatory instrument is required to improve the practice of small-scale mining (e.g. Lawal 2002), especially to curb illegal mining activities in an area such as Ijero where regulatory oversight is reportedly weak. And to ensure sustainable extractive practice, public participation is highly important. The computed RAI variance was 0.04276 , with a standard deviation of 0.20 and co-efficient of variation of $4.93 \%$. Based on this computation, it could be deduced that the scatter around the mean of RAI was low, the level of responses by the residents were very close and not far from each, which implies that all measures are considered relevant to a more sustainable mining regulation in the community.

\section{Conclusion and policy implications}

This study was aimed at exploring risk tolerance level of households to small scale mining activities in a southwestern Nigerian community. A structured household survey of 506 households was the major source of data. We had anticipated that residents might show low tolerance to all 21 indicators used in the survey, particularly those affecting the natural environment, but obviously, there are other factors at play which are worthy of investigation both locally and internationally. Results indicate that residents are more concerned about the social effects of mining than the associated biophysical impacts, but show strong support for improved regulatory oversights of mining activities in the community. It also seems that risk perception of mining activities in the area does not rely on long-term environmental impacts per se, but more determined by the context of immediate gains to the community. This was perhaps a function of residents' low economic status where majority fall below the minimum wage, and continue to show optimism despite the risk and sustainability of the practice. This aligns with the concept of optimism bias and the predisposition towards the immediate social and interactional elements that influence mining communities' risk decisions as captured in the situated rationality theory.

Before developing policy options for the study area and similar jurisdictions, environmental managers and regulators should consider that our sample was drawn from the local population which represents a restrictive context. The level of tolerance towards specific variables is likely to vary by the severity of the problem within a local context. It is important that managers consider the severity of impacts relative to each location and residents' specific concerns before developing a blueprint for monitoring small-scale mining activities. In essence, a multicase locational analysis of regions and communities within a nation-state context is necessary to formulate adequate responses that will address both best practice and local concerns, a pressing research agenda in many developing economies. Second, the residents' emphasis on the social aspects of mining effects suggests that status quo may persist if their economic needs are being met despite significant health and social risks associated with unregulated mining practices. However, literature on sustainable mining development suggests that most individuals may be willing to review their perception of exposure to risk if they clearly understand wider implications of their continuous involvement (e.g. Heemskerk 2003).

Public engagement in any regulatory effort therefore is essential to (1) increase awareness of the need to consider less risky economic alternatives; (2) inform local population about why certain regulatory actions are proposed; and (3) help to successfully implement proposed long-terms solutions to risks associated with unsustainable mining practice at any scale. The consequences of all these for local sustainability in the context of developing nations largely revolve around capacity to keep up with global best practices as well as problems of effective resource governance. While this is ultimately a government responsibility, community-led initiatives to support and enhance capacity will be valuable for sustainable mining practices. For example, it may be appropriate for residents to take a more active role in increasing risk awareness and in pushing for stronger regulatory oversights. Creating such capacity may increase the ability to understand local concerns and perceptions and integrating them into the planning, management and policy processes for the community. This would ideally create a greater consistency between local and institutional responses for designing long-term solutions. 
Afon, A. (2006). The use of residents' satisfaction index in selective rehabilitation of urban core residential areas in developing countries. International Review for Environmental Strategies, 6(1), 137-152.

Aigbedion, I. and Iyayi, S. (2007). Environmental effects of mineral exploitation in Nigeria. International Journal of Physical Science, 2(2), 33-38.

Akabzaa, T. and Darimani, A. (2001). Impact of mining sector investment in Ghana: A study of Tarkwa mining region. A draft report prepared for Structural Adjustment Participatory Review International Network. Retrieved from http://www.saprin.org/ghana/research/gha_mining.pdf

Ale, P., Dada, J., and Adewumi, A. (2014). Industrial minerals potentials of Ijero pegmatite in Ekiti State, Southwestern Nigeria. World Applied Sciences Journal, 29 (3), 415-420.

Armah, F., Luginaah, I., and Odoi, J. (2013). Artisanal small-scale mining and mercury pollution in Ghana: a critical examination of a messy minerals and gold mining policy. Journal of Environmental Studies and Sciences, 3:381-390.

Talabi, A., Afolagboye, L., Aladejana, J., Akinola, O., and Aturamu, A. (2015). Assessment of impacts of artisanal and small-scale mining activities on groundwater quality of Ijero-Ekiti, South-Western Nigeria. International Journal of Innovative Research in Science, 4(4), 2194-2206.

Babatunde, O., Ayodele, L., Elegbede, O. Babatunde O., et al. (2013). Practice of occupational safety among artisanal miners in a rural community in southwest Nigeria. International Journal of Science, Environment, and Technology, 2(4), 622-633.

Boateng, D., Codjoe N., and Ofori, J. (2014). Impact of illegal small scale mining (galamsey) on cocoa production in Atiwa District of Ghana. International Journal of Advanced Agricultural Research, 2, 89-99.

Bose-O'Reilly, S., Drasch, G., Beinhoff, C., Rodrigues-Filho, S. et al. (2010). Health assessment of artisanal gold miners in Indonesia. Science of the Total Environment, 408: 713-725.

Bose-O'Reilly, S., Lettmeier, B., Gothe, R., Beinhoff, C., et al. (2008). Mercury as a serious health hazard for children in gold mining areas. Environmental Research, 107: 89-97.

Crickette, G., Demian, R., Fox, C., Hach, J., Mokamaski, J., Mazumdar, R., and McGuire, R. (2012). Exploring Risk Appetite and Risk Tolerance. Risk and Insurance Management Society: Retrieved from: https://www.rims.org/resources/ERM/Documents/RIMS_Exploring_Risk_Appetite_Risk_Tolerance_0412.p df

Ekiti State Government (2014). Population Figures. Retrieved from http://ekitistate.gov.ng/aboutekiti/population-figures/

Faircheallaigh, O., Regan, A., Kikira, D., and Kenema, S. (2016). Small Scale Mining in Bougainville: Impact and Policy Responses. Interim report on research findings by Australian Development Research Awards Scheme (ADRAS). Nathan QLD: Griffith University.

Faweya, E. and Oniya, E. (2012). Radiological safety assessment and physico-chemical characterization of soil mixed with mine tailings used as building materials from Oke-Kusa mining sites In Ijero, Nigeria. Nature and Science, 10(5), 64-71.

Galizzi, M. and Tempesti, T. (2014). Workers' perceptions of risk and occupational injuries. Paper submitted to the "Risk, Perception, and Response" Conference (Harvard University, March 2014). Retrieve from: https://cdn1.sph.harvard.edu/wpcontent/uploads/sites/1273/2014/03/Risk_Perception_Galizzi_Tempesti_March_update.pdf

Grätz, T. (2009). Moralities, risk and rules in West African artisanal gold mining communities: A case study of Northern Benin. Resources Policy, 34(1-2), 12-17.

Hayes, K. and R. Perks (2012). Women in the artisanal and small-scale mining sector of the Democratic Republic of the Congo. In: P. Lujalaand S. Rustad (eds.), High-Value Natural Resources and Peacebuilding. London: Earthscan.

Heemskerk, M. (2003). Risk attitudes and mitigation among gold miners and others in the Suriname rainforest. Natural Resources Forum, 27(4), 267-278.

Inouye, J. (2014). Risk Perception: Theories, Strategies, and Next Steps. Itasca, IL: Campbell Institute National Safety Council.

Kambani M. (1998). The Economic and Environmental Implications of Small-Scale Mining in Developing Countries. Dar es Salaam: University of Dar es salaam. Pp. 13-27.

Labonne, B. and Gilman, J. (1999). Towards building sustainable livelihoods in the artisanal mining communities. Paper presented at the Tripartite Meeting on Social and Labour Issues in Small-scale mines, 17-21 May. Geneva: International Labour Organization.

Lar, U., Ngozi-Chika C., and Tsuwang, K. (2014). Environmental health impact of potential harmful element discharges from mining operations in Nigeria. American Journal of Environmental Protection, 3(6-2), 14-18.

Lawal, M. (2002). Constraints to small-scale mining in Nigeria: policies and strategies for development. Centre for Energy Petroleum Minerals Law and Policy Annual Review - the Dundee Yearbook of International Natural Resources and Energy Law and Policy, pp. 17. 
Limbong, D., Kumampung, J., Rimper, J., Arai, T. and Miyazaki, N. (2003). Emissions and environmental implications of mercury from artisanal gold mining in north Sulawesi, Indonesia. Science of the Total Environment, 302: 227-236.

Lungu, J. and Shikwe, A. (2007). Cooperative Social Responsibility Practices in Small Scale Mining on the Copper Belt: A Baseline Study. Netherlands Institute for Southern Africa, Briefing paper 2007. Retrieved from: http://www.groundwork.org.za/specialreports/ZCTU.PDF.

Luning, S. (2014). The future of artisanal miners from a large-scale perspective: From valued pathfinders to disposable illegals? Futures, 62(Part A), 67-74.

Meyer, J. and Gagne, M. (2008). Employee engagement from a self-determination theory perspective. Industrial and Organizational Psychology, 1, 60-62.

Ogungbemi, O., Alu, O., and Ologe, O. (2014). Integrated geophysical approach to solid mineral exploration: a case study of Kusa Mountain, IjeroEkiti, Southwestern Nigeria. The Pacific Journal of Science and Technology, 15(1), 426-432.

Okunlola, O. and Akinola, O. (2010). Petrochemical characteristics of the Precambrian rare metal pegmatite of Oke Asa area, southwestern Nigeria: Implication for Ta-Nb mineralization. RMZ Materials and Geoenvironment, 57(4), 525-538.

Omorede, C. (2014). Assessment of the impact of oil and gas resource exploration on the environment of selected communities in Delta State, Nigeria. International Journal of Management, Economics and Social Sciences, 3(2), 79-99.

Organization for Economic Cooperation and Development (2002). Environmental impacts of foreign direct investment in the mining sector in sub-Saharan Africa. Conference on Foreign Direct Investment and the Environment, 7-8 February. Paris, France: OECD.

Zamora, A. (2000). Small-scale mining: a social and environmental problem turned into an opportunity for economic development. Internet Journal of the Centre for Energy, Petroleum and Mineral Law and Policy, 6(6); Retrieved from: www.dundee.ac.uk/cepmlp/journal/html/article6-6.html 